\title{
Dysfunction by Disclosure? Stereotype Threat as a Source of Secondary Neurocognitive Malperformance in Obsessive-Compulsive Disorder
}

\author{
Steffen Moritz, Karla Spirandelli, Insa Happach, Despina Lion, AND Fabrice Berna \\ University Medical Center Hamburg-Eppendorf, Department of Psychiatry and Psychotherapy, Hamburg, Germany \\ (Received September 10, 2017; Final Revision November 18, 2017; Accepted January 25, 2018; First Published Online March 19, 2018)
}

\begin{abstract}
Objectives: There is mixed evidence regarding whether patients with obsessive-compulsive disorder (OCD) display substantial neurocognitive deficits. Several studies implicate poor motivation, comorbid disorders, or distraction due to obsessive thoughts as potential causes of secondary malperformance. The present study examined the impact of stereotype threat (i.e., confrontation with a negative stereotype may impair performance) on neuropsychological functioning in individuals with OCD. We hypothesized that a stereotype threat cue emphasizing neurocognitive deficits in OCD (as is often conveyed in disclosure and consent documents that inform patients about the purpose of a study) would compromise patients' test performance relative to a control group who did not receive such cue. Methods: Fifty participants with either a verified or a likely diagnosis of OCD were recruited online and randomly assigned to either an experimental condition aimed to elicit stereotype threat or a control condition. Both groups underwent (objective) memory and attention (Go/NoGo task) assessments and completed questionnaires capturing psychopathology, cognitive complaints, and self-stigma. Results: As hypothesized, patients in the stereotype threat condition performed worse on the Go/NoGo task. Groups did not differ on any other measures. Conclusions: Stereotype threat negatively impacted neuropsychological performance on an attention task. The threat cue was perhaps too weak or the stereotype threat was already internalized by the patients and "saturated" at baseline so that no effect emerged on the other measures. Implications for clinical trials are discussed. (JINS, 2018, 24, 584-592)
\end{abstract}

Keywords: obsessive-compulsive disorder, stereotype threat, neuropsychology, stigma

\section{INTRODUCTION}

In the days of Sigmund Freud, obsessive-compulsive disorder (OCD) was deemed the prototype of a neurotic disorder and was regarded as both amenable to understanding and psychological treatment (Freud, Strachey, Freud, Strachey, \& Tyson, 1909). Psychoanalytic models were the starting point of contemporary OCD research; these assumed an unresolved conflict in OCD between the urges from the so-called "id" that collide with the hypermoral demands of the so-called "superego" (Freud, 1963; Moritz, Kempke, Luyten, Randjbar, \& Jelinek, 2011). The merits of psychological models of OCD are undisputed to this day. Yet, cognitive behavioral therapy has replaced psychoanalysis

Correspondence and reprint requests to: Steffen Moritz, University Medical Center Hamburg-Eppendorf, Department of Psychiatry and Psychotherapy, Martinistr. 52, 20246, Hamburg, Germany. E-mail: moritz@uke.uni-hamburg.de as the primary (evidence-based) treatment for OCD (Gava et al., 2007; Skapinakis et al., 2016).

Paralleling trends in other fields of psychopathology research (e.g., depression, schizophrenia), the interest in biological models of OCD is on the rise (Abramovitch, Abramowitz, \& Mittelman, 2013; Hu et al., 2017; Peng et al., 2012; Rotge et al., 2010). This type of research is stimulated by studies indicating that OCD is associated with neuropsychological deficits across several domains (Abramovitch et al., 2013; Benzina, Mallet, Burguière, N'Diaye, \& Pelissolo, 2016; Kuelz, Hohagen, \& Voderholzer, 2004; Shin, Lee, Kim, \& Kwon, 2014; Snyder, Kaiser, Warren, \& Heller, 2015; Tallis, 1997), particularly nonverbal memory and executive functioning, allegedly stemming from brain deficits in areas such as the (orbito-)frontal cortex (Hu et al., 2017; Pauls, Abramovitch, Rauch, \& Geller, 2014; Peng et al., 2012; Piras et al., 2015; Rotge et al., 2010).

Several researchers advocate the idea that neurocognitive deficits may represent endophenotypes of the disorder 
(Chamberlain, Blackwell, Fineberg, Robbins, \& Sahakian, 2005; Robbins et al., 2012; Snyder et al., 2015). The account that OCD is an entirely psychological disorder has accordingly crumbled. This inference is, however, not completely undisputed in view of some recent findings indicating that contextual factors such as poor motivation (Moritz, Hauschildt, Saathoff, \& Jelinek, 2017; Moritz, Hottenrott, Jelinek, Brooks, \& Scheurich, 2012), threatened morality (Kalanthroff, Aslan, \& Dar, 2017), comorbid disorders (Basso, Bornstein, Carona, \& Morton, 2001; Moritz et al., 2001), and interference with symptoms (Abramovitch, Dar, Hermesh, \& Schweiger, 2012) contribute to poorer test performance in patients with OCD (see below). Of interest, similar moderators are being discussed for other disorders, for example schizophrenia (Fervaha et al., 2014; Krkovic, Moritz, \& Lincoln, 2017; Moritz et al., 2017).

Psychological and biological models are not mutually exclusive. Clearly, every cognition and emotion has a biological substrate, and for more than 25 years we have known that psychotherapy in OCD impacts brain functioning (Baxter, 1992). Freud himself was interested in the physiological correlates of psychological processes (Centonze, Siracusano, Calabresi, \& Bernardi, 2004; Freud, 1953). Yet, contemporary research suggests widespread structural abnormalities within the frontal-striatal network in OCD (Hu et al., 2017; Peng et al., 2012) rather than subtle, temporal, and changeable biological alterations.

OCD is associated with both stigma (Fennell \& Liberato, 2007; Warman, Phalen, \& Martin, 2015) and self-stigma, which is one of the major reasons for treatment abstinence in the disorder (García-Soriano, Rufer, Delsignore, \& Weidt, 2014; Marques et al., 2010). Self-stigma is rooted in the deep worry of many individuals with OCD that they are dangerous to loved ones or the public. Stigma and self-stigma are pronounced in patients with taboo thoughts (e.g., thoughts about harming other people; Glazier, Wetterneck, Singh, \& Williams, 2015; McCarty, Guzick, Swan, \& McNamara, 2017), fueling their fears about involuntary hospitalization (Glazier et al., 2015). Fear of resentment by co-workers and by potential partners was endorsed frequently in one of the earliest studies on this topic (Stengler-Wenzke, Beck, Holzinger, \& Angermeyer, 2004).

Anti-stigma campaigns fostering awareness and understanding of psychological disorders often convey that those with mental disorders are not dangerous and that the sufferers have a biological vulnerability (Briffault, Morvan, \& Roscoät, 2010; Lincoln, Arens, Berger, \& Rief, 2008; Wiesjahn, Jung, Kremser, Rief, \& Lincoln, 2016) and thus cannot be held fully responsible for their occasionally disturbing ideas and actions. Biological models, such as the idea that OCD reflects a disturbance in the basal ganglia or orbito-frontal cortex (for one of the most influential models, see Saxena, Brody, Schwartz, \& Baxter, 1998), may decrease the burden of shame in some patients by reducing their self-blame (as captured by the famous quote "It is not me but my OCD") (Angermeyer, Holzinger, Carta, \& Schomerus, 2011) but may in turn create negative consequences with regard to stigma and self-stigma.
Indeed, studies show that biogenetic models increase endorsement of the stereotype that people with psychological problems are dangerous (Kvaale, Haslam, \& Gottdiener, 2013). Another negative consequence of biological models is fatalism regarding treatment. In a recent study (Moritz et al., 2016), 36\% of individuals with OCD endorsed that having a brain disorder likely means that psychotherapy is not effective. To conclude, biogenetic models may harm patients' self-esteem and compromise treatment outcomes. This is particularly troublesome if the studies these models rely on exaggerate the real degree of deficits and/or only apply to a subgroup of patients.

Our study tested the hypothesis that stereotype threat contributes to poor neuropsychological performance in people with OCD. Stereotype threat is a well-established (social) psychological effect. It denotes the phenomenon that performance is compromised when an individual is confronted with a devaluing stereotype or stigma-related information (Schmader, Johns, \& Forbes, 2008; Steele \& Aronson, 1995). The effect is ubiquitous and has been demonstrated across various groups, including people of different races, genders, and ages (Derks, Inzlicht, \& Kang, 2008; Gonzales, Blanton, \& Williams, 2002; Hess, Auman, Colcombe, \& Rahhal, 2003; Levy \& Langer, 1994; Spencer, Steele, \& Quinn, 1999; Steele, 1997; Steele \& Aronson, 1995). To illustrate, Spencer et al. (1999) tested the impact of the stereotype that women are worse at math than men in actual performance. As hypothesized, women performed less well than men in difficult math exercises when the exercises were framed as producing gender differences. In contrast, men and women performed equally well in a condition without stereotype threat.

Stereotype threat has also been studied in people with brain impairment. In a study on 36 participants with a history of mild head injury (Suhr \& Gunstad, 2002), the stereotype (i.e., diagnosis) threat group performed worse than the neutral group on general intellect and memory, whereas no differences occurred for basic attention or psychomotor speed. To date, very few studies have looked at stereotype threat in people with mental disorders. In a study on 30 patients with schizophrenia who underwent each a stereotype threat and a control condition, patients' social skills were rated as worse in the stereotype threat condition by an observer who did not know about the diagnostic status of the patient (Henry, Hippel, \& Shapiro, 2010). To the best of our knowledge, no study has looked at stereotype threat in OCD, yet.

The present study was designed to transfer this line of research to the field of neurocognition in OCD. Neurocognitive assessments are common in OCD research and may be prone to the effects of stereotype threat. This is because, before the start of a study, its rationale must be disclosed to patients, and the rationale may in some cases contain hypotheses about circumscribed brain and neurocognitive impairments in OCD. In view of the mixed findings on neurocognitive performance in OCD and some initial evidence of major influences contributing to secondary impairment such as poor motivation (Moritz et al., 2017, 2012) and interference with symptoms (Abramovitch et al., 2012), we aimed to examine whether stereotype threat compromises neuropsychological performance in individuals with OCD. 
A hospital environment, where such tests usually are carried out, may induce a strong stereotype threat, thereby potentially creating a ceiling effect. To prevent this, we pursued our hypothesis using an online assessment. Individuals were randomized to either a stereotype threat condition (they were told that neurocognitive deficits exist in mental disorders, for example, OCD) or a control condition (neutral text) and were then administered neuropsychological tests and several selfreport scales on self-stigma, subjective cognition, and symptoms. We expected that participants in the stereotype threat condition would display a poorer performance on the neuropsychological tests than participants who were not given such cue. We chose a memory test and a task of inhibitory control as deficits have been implicated in these domains (Chamberlain et al., 2005; Lipszyc \& Schachar, 2010; Shin et al., 2014).

\section{METHODS}

\section{Participants}

Participants were drawn from online forums for people with OCD as well as a mailing list of former patients with a verified diagnosis of OCD. The latter subgroup had agreed to be contacted for future research studies. Informed consent was obtained from all participants before the assessment started. The study was approved by the Ethics Committee of the Medical Board Hamburg. The initial sample consisted of 63 participants who had been formerly treated for OCD or had disclosed a formally established diagnosis of OCD (and were still displaying symptoms). All completed the questionnaires and neuropsychological tests. Participants were excluded if they had severe neurological symptoms (e.g., stroke, brain injury), if their age was below 18 or above 70 , or if their OCD symptoms were no longer present. Comorbid psychiatric disorders, except for schizophrenia and bipolar disorder, were tolerated. Depression was the most common comorbid disorder.

Data from 13 individuals were discarded from the analyses because of a neurological disorder $(n=2$; cerebral paresis as a child, stroke), low scores on the Yale-Brown Obsessive Compulsive Scale (Y-BOCS; see below, $n=2$, score $=0$ ), technical problems with the $\mathrm{Go} / \mathrm{NoGo}$ task $(n=3$; e.g., the task did not work on an iPad), and age over $70(n=1)$. Moreover, data from 5 of these 13 participants were deleted blind to results to balance the subsamples as to age and gender, which were initially significantly different between the stereotype threat and the control condition. ${ }^{1}$ Of the final sample, 24 were allocated to the experimental condition and 26 to the control condition. According to G*Power (Erdfelder, Faul, \& Buchner, 1996), this sample size is sufficient

\footnotetext{
${ }^{1}$ Unfortunately, there is no gold standard regarding how to deal with group differences on baseline variables. We chose a conservative approach because accounting for baseline differences using ANCOVA may not address the problem fully. Importantly, group differences emerged before reduction of the sample size.
}

to yield a significant group difference at a medium effect size $(d=.5)$ with a power of 0.80 . No group differences emerged for baseline demographic characteristics and psychopathology (see Table 1). Forty-three participants in the final sample provided information on their current psychotropic medication (none, $n=14$; antidepressant medication only, $n=26$; St. John's Wort, $n=1$; antidepressant and antipsychotic medication in combination, $n=1$; other, $n=1$ ).

\section{Tasks and Procedure}

The online study was set up using the Questback Unipark ${ }^{\circledR}$ software. Individuals received a link to the study and were then randomly assigned to either the experimental group that received a stereotype threat cue or the control group that did not receive a stereotype threat cue. Both groups completed the same battery of neuropsychological tests and questionnaires. The entire assessment lasted approximately $40 \mathrm{~min}$. The only difference between the two conditions was that the experimental group was given the following subtle stereotype threat cue: "Scientific studies have shown that patients with mental disorders (e.g., psychosis, OCD, etc.) have mild brain disorders as well as difficulty concentrating and remembering new information. The two following tests are designed to measure your cognitive abilities".

In contrast, the control group received the following rather neutral text: "The following two tests in this study are being examined for their usability." Toward the end of the experimental procedure, participants were asked to state which introductory information (stereotype threat cue, neutral text [control], none) they had been shown. This was done to check whether the cue had been memorized properly or perhaps had been overlooked and whether patients in the control condition had a false memory and remembered a threat cue when in fact none was presented.

Upon completion of the study, participants received a manual that teaches relaxation exercises plus an audio file. This had been announced as an incentive for participation at the beginning of the trial. They were also debriefed about the purpose of the study.

\section{Neuropsychological Tests}

Neuropsychological performance was measured by two standard tests that were adapted for online administration. Selective attention and executive functioning were assessed using an online Go/NoGo task, which is frequently regarded as a test of executive functioning and response inhibition (Ritsner, Blumenkrantz, Dubinsky, \& Dwolatzky, 2006; Weisbrod, Kiefer, Marzinzik, \& Spitzer, 2000), and deficits in these two domains have been implicated in OCD for many years (Chamberlain et al., 2005). Participants were asked to respond to a target ("Go", in this case the black letter "X") by directly clicking on it and to inhibit responses to distractor ("NoGo") stimuli (i.e., a red "X" or "+" or a black “+"). Individuals were presented with 10 targets and 30 distracters (10 of each subtype). 
Memory was assessed using the German adaptation of the Auditory Verbal Learning Test (Verbal Learning and Memory Test, VLMT) (Helmstaedter, Lendt, \& Lux, 2001; Schmidt, 1996; Volz-Sidiropoulou, Poll, Forkmann, \& Gauggel, 2010). Participants were visually presented 15 words in a row for $3 \mathrm{~s}$ each. The list of words was shown three times. Participants had to remember and enter as many items as possible (e.g., hat, bell, coffee) in a designated space on the webpage after each presentation of the sequence. The words were easy to visualize; the VLMT thus taps both verbal and nonverbal memory. After each set of 15 words, participants were asked to enter the words they remembered, in any order. After a section in which self-report questionnaires were administered (see below), a delayed recall test was given with no interim presentation of items. This was followed by a recognition test encompassing both the already studied (i.e., old) and the new words. Participants had to assess whether a word had been previously presented. The test-retest reliability of the German version of the VLMT is satisfactory $(r=.68-.87$; Helmstaedter et al., 2001).

\section{Self-Report Questionnaires}

All questionnaires were presented to both groups after the cognitive tasks to rule out the possibility that the items of the scales induced stigma.

Subjective cognitive dysfunction was tapped with the Subjective Scale to Investigate Cognition in Schizophrenia (SSTICS), a 21-item scale that quantifies different cognitive domains (e.g., memory, attention, language, and praxia) in patients (Stip, Caron, Renaud, Pampoulova, \& Lecomte, 2003). The SSTICS was originally constructed to tap deficits frequently observed in schizophrenia but also other disorders. Participants are asked to endorse how often they have noticed cognitive impairments in their daily life in the past two weeks using a 5-point Likert scale (very often, often, sometimes, seldom, never). For the current study, the SSTICS was divided into two parts. As mentioned, items related to stigma were shown after completion of the neuropsychological tests, as these might have acted as an additional stereotype threat cue (e.g., Do you have difficulties remembering the names of your medication?" or "Do you forget to take your medication?").

Self-stigma was assessed by the Internalized Stigma of Mental Illness (ISMI) scale. The ISMI contains subscales measuring alienation, stereotype endorsement, perceived discrimination, social withdrawal, and stigma resistance on a 4-point Likert scale (i.e., strongly disagree, rather disagree, rather agree, strongly agree) (Boyd, Adler, Otilingam, \& Peters, 2014; Boyd Ritsher, Otilingam, \& Grajales, 2003). The German version of the ISMI shows high internal consistency (Cronbach's $\alpha=.92)$ as well as good test-retest reliability $(r=.71)$.

The Patient Health Questionnaire (PHQ-9) (Löwe, Kroenke, Herzog, \& Gräfe, 2004) taps depressive symptoms on a 4-point scale (not at all, on some days, on the majority of days, nearly every day) with reference to the past 2 weeks. It is regarded as a valid and reliable screening instrument for depression (Cronbach's $\alpha=.88$ ).

\section{Statistical Analyses}

We used both conventional and Bayesian analysis methods to compare sociodemographic variables, self-report questionnaires, and cognitive performance. Two statistical methods were adopted as there is a growing debate whether " $p$-value statistics" is outdated and Bayesian statistics is a superior alternative. This debate has not been resolved (Holtmann, Koch, Lochner, \& Eid, 2016; Ma et al., 2009), so we used these two statistical methods to ensure that our findings will be meaningful years from now if the scientific community ends up favoring one method over the other. For the Bayesian analyses, we used very lowly informative priors for the univariate analyses (normal distribution $N$ [mean \pm standard deviation] for the $\log -\mathrm{OR}=N\left[0 ; 10^{2}\right]$ ), which amounts to expecting an odds ratio (OR) equal to 1 with a $95 \%$ credible interval (CI) of 0.001 to 1000 .

Results are presented for each potential predictor as an OR with a 95\% CI, with the probability $(\mathrm{Pr})$ of the OR being above $1(\operatorname{Pr}[\mathrm{OR}>1])$. A large $\operatorname{Pr}(\mathrm{OR}>1)$ value (e.g., $>0.95,>0.975$, or 0.99 ) must be interpreted as indicating lower values for the individuals in the stereotype threat condition compared to controls. A small value of $\operatorname{Pr}(\mathrm{OR}>1)$, for instance, $<0.05,0.025$, or 0.01 , reflects higher values for the individuals in the stereotype threat condition compared to the controls (the stereotype threat was coded with 1 and the control condition with 2). It is worth noting that the probability $\operatorname{Pr}$ $(\mathrm{OR}>1)$ can be interpreted as $1-\operatorname{Pr}(\mathrm{OR}<1)$. Thus, probability values near 1 and 0 both indicate a significant effect.

\section{RESULTS}

The results in Table 1 show that the two groups did not differ in terms of age, sex ratio, or psychopathological scales. Patients showed mild depression and low OCD symptom severity. Most patients had minimal to mild self-stigma, according to the scoring recommendations of Lysaker, Roe, and Yanos (2007). The two groups did not differ on medication status (on $v s$. off), $\chi^{2}(1)=0.803 ; p=.370$ ), or on prevalence of comorbid depression, $\chi^{2}(1)=0.12, p=.729$.

Similarly, the two groups did not differ on SSTICS or ISMI scores (see Table 1). With regard to cognitive performance, individuals in the stereotype threat condition had a probability of $94.7 \%$ of obtaining fewer hits than the controls on the Go/NoGo task (Bayesian statistics). Using conventional statistics, the groups showed a significant difference. According to Bayesian statistics, there was a $99.9 \%$ probability that patients in the stereotype threat condition would have more false alarms than the controls on the Go/NoGo tests. This finding, however, was not observed using conventional statistics (neither parametric nor non-parametric tests), as the data had a Poisson distribution and were not normally distributed. No group difference was observed for the VLMT test with either procedure.

Sensitivity analyses were performed for cognitive tests and examined the effects of priors, expecting that the ORs of the differences between the participants in the stereotype threat 
Table 1. Demographic, psychopathological, and neurocognitive data, using Bayesian and conventional statistics

\begin{tabular}{|c|c|c|c|c|c|c|c|c|}
\hline \multirow[b]{2}{*}{ Variables } & \multicolumn{2}{|c|}{$\begin{array}{l}\text { Stereotype threat } \\
\qquad(n=24)\end{array}$} & \multicolumn{2}{|c|}{$\begin{array}{l}\text { Control } \\
(n=26)\end{array}$} & \multicolumn{3}{|c|}{ Bayesian statistics } & \multirow[b]{2}{*}{ t-Test } \\
\hline & $M$ & $S D$ & $M$ & $S D$ & OR & $95 \% \mathrm{CI}$ & $\operatorname{Pr}(\mathrm{OR}>1)$ & \\
\hline \multicolumn{9}{|l|}{ Sociodemographic variables } \\
\hline Age & 38.17 & $(7.92)$ & 43.77 & $(14.05)$ & 1.28 & {$[0.86,1.85]$} & 0.880 & $t(48)=1.75, p=.087, d=.49$ \\
\hline Gender (female/male) & $21 / 3$ & & $18 / 8$ & & 0.45 & {$[0.08,1.35]$} & 0.066 & $\chi^{2}(1)=2.43, p=.119$ \\
\hline \multicolumn{9}{|l|}{ Clinical variables } \\
\hline PHQ-9 & 11.18 & $(7.10)$ & 10.52 & $(4.66)$ & 0.80 & {$[0.43,1.38]$} & 0.185 & $t(45)=0.38, p=.704, d=.11$ \\
\hline Y-BOCS total & 17.33 & $(6.61)$ & 16.50 & $(5.38)$ & 1.02 & {$[0.68,1.47]$} & 0.506 & $t(48)=0.49, p=.626, d=.14$ \\
\hline \multicolumn{9}{|l|}{ Self-Report Scales } \\
\hline SSTICS Total Score & 71.82 & $(12.44)$ & 74.69 & $(12.76)$ & 1.31 & {$[0.70,2.56]$} & 0.782 & $t(46)=0.78, p=.437, d=.23$ \\
\hline ISMI Total Score & 2.02 & $(0.47)$ & 1.97 & $(0.49)$ & 0.92 & {$[0.49,1.58]$} & 0.328 & $t(45)=0.34, p=.736, d=.10$ \\
\hline \multicolumn{9}{|l|}{ Go/NoGo Test } \\
\hline Target hits (black X; maximum: 10) & 6.37 & $(3.94)$ & 8.38 & $(2.95)$ & 1.91 & {$[0.88,3.63]$} & 0.947 & $t(48)=2.03, p=.049, d=.58$ \\
\hline False alarms (maximum: 30 ) & 0.67 & $(2.26)$ & 0.27 & $(0.45)$ & 0.30 & {$[0.11,0.61]$} & 0.001 & $t(48)=0.88, p=.384, d=.24$ \\
\hline \multicolumn{9}{|l|}{$V L M T$} \\
\hline Immediate hits (maximum: 15) & 9.92 & $(1.74)$ & 9.85 & $(2.60)$ & 1.05 & {$[0.71,1.48]$} & 0.566 & $t(48)=0.11, p=.912, d=.03$ \\
\hline Immediate false positives & 0.12 & $(0.34)$ & 0.38 & $(0.90)$ & 1.25 & {$[0.70,2.07]$} & 0.746 & $t(48)=1.37, p=.179, d=.38$ \\
\hline Delayed hits (maximum: 15) & 10.46 & $(4.55)$ & 11.69 & $(2.43)$ & 1.53 & {$[0.77,2.72]$} & 0.877 & $t(48)=1.21, p=.232, d=.34$ \\
\hline Delayed false positives & 0.04 & $(0.21)$ & 0.12 & $(0.43)$ & 7.02 & {$[0.18,43.35]$} & 0.697 & $t(48)=0.73, p=.471, d=.24$ \\
\hline
\end{tabular}

Notes. $95 \% \mathrm{CI}=95 \%$ credible interval, $\operatorname{Pr}(\mathrm{OR}>1)=$ probability that $\mathrm{OR}$ is superior to 1 ; ISMI = Internalized Stigma of Mental Illness (the total score does not include the stigma resistance scale); OR = odds ratio; PHQ-9 = Patient Health Questionnaire-9; SSTICS = Subjective Scale to Investigate Cognition in Schizophrenia; VLMT = Verbal Learning and Memory Test; Y-BOCS = Yale Brown Obsessive-Compulsive Scale.

condition and the controls would be $1.3,1.5$, or 2 . The estimated ORs remained unchanged (data not shown), suggesting that the estimates of ORs were mostly driven by the data we collected and were not sensitive to priors (i.e., expected results).

We then ran multivariate analyses of the cognitive tests after adjusting for age and gender. The Deviance Index Criteria improved in comparison to the univariate models, showing that these variables were relevant predictors. Results of both the Go/NoGo and VLMT tests remained roughly unchanged, with the exception that the probability that individuals in the stereotype threat condition would have fewer hits than the controls on the Go/NoGo task increased from $94.7 \%$ (the result of the univariate model; see above) to $96.0 \%$. Using frequentist statistics, group differences numerically increased for the Go/NoGo paradigm, $p=.037$, to a medium to strong effect $\left(\eta_{\text {partial }}^{2}=.90\right)$.

Finally, we explored the possibility that stereotype threat may interact with the level of internalized stigma by examining the interaction between group and internalized stigma. Results with Bayesian statistics showed no interaction between group and internalized stigma $(\mathrm{OR}=0.83$, CI [0.147-2.734], Pr $(\mathrm{OR}>1)=0.266)$. A two-way ANOVA (using median split of ISMI total score; high $v s$. low) yielded similar results $(p>.2)$.

A manipulation check showed that nine participants could not remember the original instruction and two participants confused the condition (the participant either reported stereotype threat although the participant was in the control condition or vice versa). The results remained unchanged when this was considered in the analyses.
We correlated objective versus subjective scores to explore patients' metacognitive awareness of their neurocognitive performance. None of the objective neurocognitive measures in Table 1 correlated with the self-report scales. Of note, the VLMT parameters did not correlate with the corresponding SSTICS memory subscale, and, likewise, the Go/NoGo parameters did not correlate with the SSTICS distractibility subscale. The subjective performance (SSTICS total score) was, however, correlated with the PHQ-9 $(r=-.463$; $p<.001)$ and stigma $(r=-.486 ; p<.001)$ but not with the Y-BOCS $(|\mathrm{r}|<.3 ; p>.05)$; a trend emerged only for obsessions $(r=-.28 ; p=.053)$. Self-stigma was correlated with depression $(r=.62 ; p<.001)$ as well as obsessions $(r=.59 ; p<.001)$ and, as a result, also with the Y-BOCS total score $(r=.47 ; p=.001)$. No correlation, however, emerged for compulsions $(r=.07 ; p=.61)$.

\section{DISCUSSION}

To the best of our knowledge, this is the first study examining whether the induction of stereotype threat compromises neuropsychological performance in individuals with OCD. The article was stimulated by equivocal findings on the magnitude and profile of neuropsychological deficits in OCD (Jelinek, Moritz, Heeren, \& Naber, 2006; Moritz et al., 2005; Moritz, Kloss, von Eckstaedt, \& Jelinek, 2009). Having said this, we need to acknowledge that the majority of evidence favors the notion of neurocognitive impairment in OCD (see introduction). Yet, researchers have recently called for caution in interpreting these findings (e.g., Kalanthroff, Teichert, et al., 2017), as many group differences are minor 
and do not amount to clinically meaningful deficits, which should only be assumed when an individual performs at least 1 or 1.5 standard deviations below the population mean (Abramovitch \& Schweiger, 2015). ${ }^{2}$

Several studies have implicated motivation and interference/distraction by symptoms as sources of secondary malperformance (Abramovitch et al., 2012; Moritz et al., $2017,2012)$. The idea that stereotype threat may play an additional role was born out of the consideration that patients undergoing neurocognitive or neurophysiological assessment for research are usually given information (e.g., when signing the informed consent) that contains statements and/or hypotheses about putative deficits in the disorder. As shown by a plethora of studies in social psychology and healthrelated contexts, such negative information may compromise performance by means of motivational, affective, physiological, and cognitive processes (Schmader et al., 2008) that divert cognitive resources and attention needed for optimal performance (this account is compatible with the attentional control theory; Eysenck, Derakshan, Santos, \& Calvo, 2007).

As expected, patients in the stereotype threat condition performed worse than those in the control condition on an executive test (Go/NoGo paradigm). Bayesian statistics also found more false alarms in the stereotype threat condition. Unexpectedly, no such differences emerged for verbal memory or any of the other self-report scales. In our view, lack of power may account for these null findings because the sample size did not allow detection of small effects. The null results thus perhaps represent false-negative findings. Moreover, the online study was conducted in participants' homes or at least in presumably nonclinical environments. This might have reduced the magnitude of stereotype threat when compared to hospital settings where biogenetic research is usually carried out. Stereotype threat may be elicited more reliably in such a "saturated" clinical setting. This argument ties in well with prior studies indicating that a too subtle threat cue may lead to lack of differences (Ozen \& Fernandes, 2011).

A related argument is that a large number of participants did not remember the cue. Nevertheless, we decided against a more blatant cue as that might have created a ceiling effect. Yet, the stereotype threat was strong enough to yield effects on inhibitory control. Alternatively, the stereotype threat may have already been deeply internalized at baseline and thus could not be further boosted by the procedure (Corrigan, Watson, \& Barr, 2006). We tested this assumption by splitting the group according to self-stigma scores, but this variable did not interact with the condition on any of the measures. Notably, however, this scale does not contain items pertaining to neurocognition.

Another limitation of our study is that the memory test was not ideally chosen as performance deficits are usually stronger with nonverbal than verbal tasks (Abramovitch et al., 2013; Muller \& Roberts, 2005; Tallis, Pratt, \& Jamani, 1999),

\footnotetext{
${ }^{2}$ We would like to thank a reviewer who commented that subtle problems that do not meet such criteria may at times have a meaningful impact on daily functioning.
}

although a recent meta-analysis reported deficits for verbal memory as well (Shin et al., 2014). Yet, all the memory items were easy to visualize, so the test involves both verbal and nonverbal processing (Moritz et al., 2009). The Go/NoGo task was perhaps more sensitive because it is a complex task and competition for cognitive resources and executive functioning plays a central role in the stereotype threat model of Schmader and colleagues (2008). Subsequent research may thus administer neurocognitive tests for which impairment has been shown before (e.g., block design, Rey figure test), and a nonclinical control group (or normative data) is recommended to elucidate whether stereotype threat is the main reason for impairment or instead augments prior deficits.

Future studies might also test participants before and after the induction of the threat cue to rule out the possibility that group differences were already present at baseline. We also must learn more about the mechanisms governing stereotype threat and how long-lived its effect is. Random administration of tasks may prove beneficial in distinguishing whether differences on tasks reflect a putative sensitivity of the task to stereotype threat or to its order in the sequence (the effect may be stronger if it immediately follows the cue). Finally, the two instructions were quite disparate in terms of content and length. Future studies should align the stereotype threat and the control instructions as far as possible to allow more straightforward conclusions.

In line with previous studies in patients with psychiatric disorders (Moritz, Ferahli, \& Naber, 2004), subjective complaints were not correlated with objective deficits, tentatively speaking for metacognitive problems in the OCD sample but were highly correlated with depression and self-stigma. Self-stigma in turn was correlated with depression as well as obsessive thoughts but not with compulsions. This is in accordance with studies suggesting that the taboo content of obsessions is a frequent cause of self-stigma (McCarty et al., 2017). Since the Y-BOCS does not differentiate according to content, we could not test the hypothesis that taboo thoughts about aggression, morality, religion, and sexuality have particularly strong connections to self-stigma.

\section{Conclusion}

The current study showed that stereotype threat impairs performance on an executive task in individuals with OCD. At the same time, we failed to demonstrate an effect on verbal memory or any of the self-report measures tapping psychopathology, self-stigma, and subjective cognition. Stereotype threat may accordingly represent a confounding variable for some but not all neurocognitive functions. For future studies, it would be worthwhile to test whether null results on memory and self-stigma reflect high baseline internalized stigma or the rather neutral testing environment. Even if subsequent studies confirm a negligible effect of stereotype threat on most domains, caution is warranted in taking neurocognitive test scores as valid proxies for patients' real cognitive status or even as an index of cognition-related brain impairment, particularly in view of an emerging set of studies 
highlighting the role of stress, distraction, test anxiety, and motivation in neurocognitive test results (see introduction).

In addition, medications, particularly antipsychotics and tranquilizers (Van Ameringen et al., 2014), which are often prescribed in OCD, may also exert a detrimental effect on performance. For future research, we recommend not including statements or hypotheses about neuropsychological deficits in informed consent/disclosure forms given to patients as they may elicit stereotype threat.

To conclude, stereotype threat is a new but potentially important field of investigation and may contribute to some of the cognitive deficits displayed by psychiatric patients in neuropsychological tests.

\section{REFERENCES}

Abramovitch, A., Abramowitz, J.S., \& Mittelman, A. (2013). The neuropsychology of adult obsessive-compulsive disorder: A meta-analysis. Clinical Psychology Review, 33, 1163-1171. http://doi.org/10.1016/j.cpr.2013.09.004

Abramovitch, A., Dar, R., Hermesh, H., \& Schweiger, A. (2012). Comparative neuropsychology of adult obsessive-compulsive disorder and attention deficit/hyperactivity disorder: Implications for a novel executive overload model of OCD. Journal of Neuropsychology, 6(2), 161-191. http://doi.org/10.1111/j.17486653.2011.02021.x

Abramovitch, A., \& Schweiger, A. (2015). Misuse of cognitive neuropsychology in psychiatry research: The intoxicating appeal of neo-reductionism. Behavior Therapist, 38(7), 187-191.

Angermeyer, M.C., Holzinger, A., Carta, M.G., \& Schomerus, G. (2011). Biogenetic explanations and public acceptance of mental illness: Systematic review of population studies. British Journal of Psychiatry, 199, 367-372. http://doi.org/10.1192/bjp.bp. 110.085563

Basso, M.R., Bornstein, R.A., Carona, F., \& Morton, R. (2001). Depression accounts for executive function deficits in obsessivecompulsive disorder. Neuropsychiatry, Neuropsychology, and Behavioral Neurology, 14(4), 241-245.

Baxter, L.R. (1992). Positron emission tomography studies of brain function in depression and obsessive-compulsive disorder. In A. Kales, C.M. Pierce \& M. Greenblatt (Eds.), The mosaic of contemporary psychiatry in perspective. New York, NY: Springer, 163-172.

Benzina, N., Mallet, L., Burguière, E., N'Diaye, K., \& Pelissolo, A. (2016). Cognitive dysfunction in obsessive-compulsive disorder. Current Psychiatry Reports, 18(9), 80. http://doi.org/10.1007/ s11920-016-0720-3

Boyd, J.E., Adler, E.P., Otilingam, P.G., \& Peters, T. (2014). Internalized Stigma of Mental Illness (ISMI) Scale: A multinational review. Comprehensive Psychiatry, 55(1), 221-231. http://doi.org/10.1016/j.comppsych.2013.06.005

Boyd Ritsher, J., Otilingam, P.G., \& Grajales, M. (2003). Internalized stigma of mental illness: Psychometric properties of a new measure. Psychiatry Research, 121(1), 31-49. http://doi. org/10.1016/j.psychres.2003.08.008

Briffault, X., Morvan, Y., \& Roscoät, E. Du. (2010). Les campagnes nationales d'information sur la depression. Une anthropologie biopsychosociale? [National information campaigns on depression. A biopsychosocial anthropology?]. L'Encéphale, 36(Suppl 2), D124-D132. http://doi.org/10.1016/j.encep.2009.05.005
Centonze, D., Siracusano, A., Calabresi, P., \& Bernardi, G. (2004). The Project for a Scientific Psychology (1895): A Freudian anticipation of LTP-memory connection theory. Brain Research Reviews. http://doi.org/10.1016/j.brainresrev.2004.07.006

Chamberlain, S.R., Blackwell, A.D., Fineberg, N.A., Robbins, T. W., \& Sahakian, B.J. (2005). The neuropsychology of obsessive compulsive disorder: The importance of failures in cognitive and behavioural inhibition as candidate endophenotypic markers. Neuroscience and Biobehavioral Reviews, 29, 399-419. http:// doi.org/10.1016/j.neubiorev.2004.11.006

Corrigan, P.W., Watson, A.C., \& Barr, L. (2006). The self-stigma of mental illness: Implications for self-esteem and self-efficacy. Journal of Social and Clinical Psychology, 25(8), 875-884. http://doi.org/10.1521/jscp.2006.25.8.875

Derks, B., Inzlicht, M., \& Kang, S. (2008). The neuroscience of stigma and stereotype threat. Group Processes \& Intergroup Relations, 11(2), 163-181. http://doi.org/10.1177/1368430207088036

Erdfelder, E., Faul, F., \& Buchner, A. (1996). GPOWER: A general power analysis program. Behavior Research Methods, Instruments, \& Computers, 28(1), 1-11. http://doi.org/10.3758/BF03203630

Eysenck, M.W., Derakshan, N., Santos, R., \& Calvo, M.G. (2007). Anxiety and cognitive performance: Attentional control theory. Emotion, 7(2), 336-353. http://doi.org/10.1037/1528-3542.7.2.336

Fennell, D., \& Liberato, A.S.Q. (2007). Learning to live with OCD: Labeling, the self, and stigma. Deviant Behavior, 28(4), 305-331. http://doi.org/10.1080/01639620701233274

Fervaha, G., Zakzanis, K.K., Foussias, G., Graff-Guerrero, A., Agid, O., \& Remington, G. (2014). Motivational deficits and cognitive test performance in schizophrenia. JAMA Psychiatry, 71(9), 1058-1065. http://doi.org/10.1001/jamapsychiatry.2014.1105

Freud, S. (1953). Project for a scientific psychology. In The Standard Edition of the Complete Psychological Works of Sigmund (pp. 283-397). London: Hogarth Press.

Freud, S. (1963). Three case histories: The "'wolf man'”, the " 'rat man'” and the psychotic Doctor Schreber. New York, NY: Collier Books.

Freud, S., Strachey, J., Freud, A., Strachey, A., \& Tyson, A. (1909). Notes upon a case of obsessional neurosis. In J. Strachey (Ed.), The standard edition of the complete psychological works of sigmund freud, volume X (1909): Two case histories ("Little Hans" and the "Rat Man") (Vol. 10, pp. 151-318). London: Hogarth Press.

García-Soriano, G., Rufer, M., Delsignore, A., \& Weidt, S. (2014). Factors associated with non-treatment or delayed treatment seeking in OCD sufferers: A review of the literature. Psychiatry Research, 220, 1-10. http://doi.org/10.1016/j.psychres.2014.07.009

Gava, I., Barbui, C., Aguglia, E., Carlino, D., Churchill, R., De Vanna, M., \& McGuire, H.F. (2007). Psychological treatments versus treatment as usual for obsessive compulsive disorder (OCD). Cochrane Database of Systematic Reviews, 2(Art. No(2), CD005333). http://doi.org/10.1002/14651858.CD005333.pub2

Glazier, K., Wetterneck, C., Singh, S., \& Williams, M.T. (2015). Stigma and shame as barriers to treatment in obsessivecompulsive and related disorders. Journal of Depression and Anxiety, 4(3), 1-5. http://doi.org/10.4191/2167-1044.1000191

Gonzales, P.M., Blanton, H., \& Williams, K.J. (2002). The effects of stereotype threat and double-minority status on the test performance of latino women. Personality and Social Psychology Bulletin, 28(5), 659-670. http://doi.org/10.1177/0146167202288010

Helmstaedter, C., Lendt, M., \& Lux, S. (2001). Verbaler Lern- und Merkfähigkeitstest (VLMT). Manual. [Verbal Learning and Memory Test (VLMT). Manual]. Beltz-Test. 
Henry, J.D., Hippel, C., \& Shapiro, L. (2010). Stereotype threat contributes to social difficulties in people with schizophrenia. British Journal of Clinical Psychology, 49(1), 31-41. http://doi.org/ 10.1348/014466509X421963

Hess, T.M., Auman, C., Colcombe, S.J., \& Rahhal, T.A. (2003). The impact of stereotype threat on age differences in memory performance. The Journals of Gerontology Series B: Psychological Sciences and Social Sciences, 58(1), P3-P11. http://doi.org/ 10.1093/geronb/58.1.P3

Holtmann, J., Koch, T., Lochner, K., \& Eid, M. (2016). A comparison of ML, WLSMV, and Bayesian methods for multilevel structural equation models in small samples: A simulation study. Multivariate Behavioral Research, 51(5), 661-680. http://doi.org/10.1080/00273171.2016.1208074

Hu, X., Du, M., Chen, L., Li, L., Zhou, M., Zhang, L., ... Gong, Q. (2017). Meta-analytic investigations of common and distinct grey matter alterations in youths and adults with obsessive-compulsive disorder. Neuroscience and Biobehavioral Reviews, 78, 91-103. http://doi.org/10.1016/j.neubiorev.2017.04.012

Jelinek, L., Moritz, S., Heeren, D., \& Naber, D. (2006). Everyday memory functioning in obsessive- compulsive disorder. Journal of the International Neuropsychological Society, 12(5), 746-749. http://doi.org/10.1017/S1355617706060899

Kalanthroff, E., Aslan, C., \& Dar, R. (2017). Washing away your sins will set your mind free: Physical cleansing modulates the effect of threatened morality on executive control. Cognition and Emotion, 31(1), 185-192. http://doi.org/10.1080/02699931.2015. 1086313

Kalanthroff, E., Teichert, T., Wheaton, M.G., Kimeldorf, M.B., Linkovski, O., Ahmari, S.E., ... Simpson, H.B. (2017). The role of response inhibition in medicated and unmedicated obsessivecompulsive disorder patients: Evidence from the stop-signal task. Depression and Anxiety, 34(3), 301-306. http://doi.org/10.1002/ da.22492

Krkovic, K., Moritz, S., \& Lincoln, T.M. (2017). Neurocognitive deficits or stress overload: Why do individuals with schizophrenia show poor performance in neurocognitive tests? Schizophrenia Research, 183, 151-156.

Kuelz, A.K., Hohagen, F., \& Voderholzer, U. (2004). Neuropsychological performance in obsessive-compulsive disorder: A critical review. Biological Psychology, 65(3), 185-236. http://doi. org/10.1016/j.biopsycho.2003.07.007

Kvaale, E.P., Haslam, N., \& Gottdiener, W.H. (2013). The "side effects" of medicalization: A meta-analytic review of how biogenetic explanations affect stigma. Clinical Psychology Review, 33, 782-794. http://doi.org/10.1016/j.cpr.2013.06.002

Levy, B., \& Langer, E. (1994). Aging free from negative stereotypes: Successful memory in China among the American deaf. Journal of Personality and Social Psychology, 66(6), 989-997. http://doi.org/ 10.1037/0022-3514.66.6.989

Lincoln, T.M., Arens, E., Berger, C., \& Rief, W. (2008). Can antistigma campaigns be improved? A test of the impact of biogenetic vs psychosocial causal explanations on implicit and explicit attitudes to schizophrenia. Schizophrenia Bulletin, 34(5), 984-994. http://doi.org/10.1093/schbul/sbm131

Lipszyc, J., \& Schachar, R. (2010). Inhibitory control and psychopathology: A meta-analysis of studies using the stop signal task. Journal of the International Neuropsychological Society, 16(6), 1064-1076. http://doi.org/10.1017/S1355617710000895

Löwe, B., Kroenke, K., Herzog, W., \& Gräfe, K. (2004). Measuring depression outcome with a brief self-report instrument: Sensitivity to change of the Patient Health Questionnaire (PHQ-9). Journal of
Affective Disorders, 81(1), 61-66. http://doi.org/10.1016/S01650327(03)00198-8

Lysaker, P.H., Roe, D., \& Yanos, P.T. (2007). Toward understanding the insight paradox: Internalized stigma moderates the association between insight and social functioning, hope, and self-esteem among people with schizophrenia spectrum disorders. Schizophrenia Bulletin, 33(1), 192-199. http://doi.org/10.1093/ schbul/sbl016

Ma, J., Thabane, L., Kaczorowski, J., Chambers, L., Dolovich, L., Karwalajtys, T., \& Levitt, C. (2009). Comparison of Bayesian and classical methods in the analysis of cluster randomized controlled trials with a binary outcome: The Community Hypertension Assessment Trial (CHAT). BMC Medical Research Methodology, 9(1), 37. http://doi.org/10.1186/ 1471-2288-9-37

Marques, L., LeBlanc, N.J., Wegarden, H.M., Timpano, K.R., Jenike, M., \& Wilhelm, S. (2010). Barriers to treatment and service utilization in an internet sample of individuals with obsessive-compulsive symptoms. Depression and Anxiety, 27(5), 470-475. http://doi.org/10.1002/da.20694

McCarty, R.J., Guzick, A.G., Swan, L.K., \& McNamara, J.P.H. (2017). Stigma and recognition of different types of symptoms in OCD. Journal of Obsessive-Compulsive and Related Disorders, 12, 64-70. http://doi.org/10.1016/j.jocrd.2016.12.006

Moritz, S., Birkner, C., Kloss, M., Jacobsen, D., Fricke, S., Böthern, A., \& Hand, I. (2001). Impact of comorbid depressive symptoms on neuropsychological performance in obsessivecompulsive disorder. Journal of Abnormal Psychology, 110(4), 653-657. http://doi.org/10.1037/0021-843X.110.4.653

Moritz, S., Ferahli, S., \& Naber, D. (2004). Memory and attention performance in psychiatric patients: Lack of correspondence between clinician-rated and patient-rated functioning with neuropsychological test results. Journal of the International Neuropsychological Society, 10(4), 623-633. http://doi.org/ $10.1017 /$ S1355617704104153

Moritz, S., Hauschildt, M., Saathoff, K., \& Jelinek, L. (2017). Does impairment in neuropsychological tests equal neuropsychological impairment in obsessive-compulsive disorder (OCD)? Momentary influences, testing attitude, and motivation are related to neuropsychological performance in OCD. Journal of ObsessiveCompulsive and Related Disorders, 14, 99-105.

Moritz, S., Hottenrott, B., Jelinek, L., Brooks, A.M., \& Scheurich, A. (2012). Effects of obsessive-compulsive symptoms on neuropsychological test performance: Complicating an already complicated story. The Clinical Neuropsychologist, 26(1), 31-44. http://doi.org/10.1080/13854046.2011.639311

Moritz, S., Kempke, S., Luyten, P., Randjbar, S., \& Jelinek, L. (2011). Was Freud partly right on obsessive-compulsive disorder (OCD)? Investigation of latent aggression in OCD. Psychiatry Research, 187(1-2), 180-184. http://doi.org/10.1016/j.psychres. 2010.09.007

Moritz, S., Klein, J.P., Desler, T., Lill, H., Gallinat, J., \& Schneider, B.C. (2017). Neurocognitive deficits in schizophrenia. Are we making mountains out of molehills? Psychological Medicine, 47, 2602-2612.

Moritz, S., Kloss, M., Jacobsen, D., Kellner, M., Andresen, B., Fricke, S., ... Hand, I. (2005). Extent, profile and specificity of visuospatial impairment in obsessive-compulsive disorder (OCD). Journal of Clinical and Experimental Neuropsychology, 27(7), 795-814. http://doi.org/10.1080/13803390490918480

Moritz, S., Kloss, M., von Eckstaedt, F.V., \& Jelinek, L. (2009). Comparable performance of patients with obsessive-compulsive 
disorder (OCD) and healthy controls for verbal and nonverbal memory accuracy and confidence: Time to forget the forgetfulness hypothesis of OCD? Psychiatry Research, 166(2-3), 247-253. http://doi.org/10.1016/j.psychres.2008.02.006

Moritz, S., Stepulovs, O., Schröder, J., Hottenrott, B., Meyer, B., \& Hauschildt, M. (2016). Is the whole less than the sum of its parts? Full versus individually adapted metacognitive self-help for obsessive-compulsive disorder: A randomized controlled trial. Journal of Obsessive-Compulsive and Related Disorders, 9, 107-115. http://doi.org/10.1016/j.jocrd.2016.04.001

Muller, J., \& Roberts, J.E. (2005). Memory and attention in obsessive-compulsive disorder: A review. Journal of Anxiety Disorders, 19(1), 1-28. http://doi.org/10.1016/j.janxdis.2003.12.001

Ozen, L.J., \& Fernandes, M.A. (2011). Effects of "diagnosis threat" on cognitive and affective functioning long after mild head injury. Journal of the International Neuropsychological Society, 17(2), 219-229. http://doi.org/10.1017/S135561771000144X

Pauls, D.L., Abramovitch, A., Rauch, S.L., \& Geller, D.A. (2014). Obsessive-compulsive disorder: An integrative genetic and neurobiological perspective. Nature Reviews Neuroscience, 15 (6), 410-424. http://doi.org/10.1038/nrn3746

Peng, Z., Lui, S.S.Y., Cheung, E.F.C., Jin, Z., Miao, G.D., Jing, J., \& Chan, R.C.K. (2012). Brain structural abnormalities in obsessive-compulsive disorder: Converging evidence from white matter and grey matter. Asian Journal of Psychiatry, 5, 290-296. http://doi.org/10.1016/j.ajp.2012.07.004

Piras, F., Piras, F., Chiapponi, C., Girardi, P., Caltagirone, C., \& Spalletta, G. (2015). Widespread structural brain changes in OCD: A systematic review of voxel-based morphometry studies. Cortex, 62, 89-108. http://doi.org/10.1016/j.cortex.2013.01.016

Ritsner, M.S., Blumenkrantz, H., Dubinsky, T., \& Dwolatzky, T. (2006). The detection of neurocognitive decline in schizophrenia using the Mindstreams Computerized Cognitive Test Battery. Schizophrenia Research, 82(1), 39-49. http://doi.org/10.1016/j. schres.2005.10.014

Robbins, T.W., Gillan, C.M., Smith, D.G., de Wit, S., \& Ersche, K.D. (2012). Neurocognitive endophenotypes of impulsivity and compulsivity: Towards dimensional psychiatry. Trends in Cognitive Sciences, 16, 81-91. http://doi.org/10.1016/j.tics.2011.11.009

Rotge, J.-Y., Langbour, N., Guehl, D., Bioulac, B., Jaafari, N., Allard, M., ... Burbaud, P. (2010). Gray matter alterations in obsessive-compulsive disorder: An anatomic likelihood estimation meta-analysis. Neuropsychopharmacology, 35(3), 686-691. http://doi.org/10.1038/npp.2009.175

Saxena, S., Brody, A.L., Schwartz, J.M., \& Baxter, L.R. (1998). Neuroimaging and frontal-subcortical circuitry in obsessivecompulsive disorder. British Journal of Psychiatry, 173(Suppl. 35), 26-37.

Schmader, T., Johns, M., \& Forbes, C. (2008). An integrated process model of stereotype threat effects on performance. Psychological Review, 115(2), 336-356. http://doi.org/10.1037/ 0033-295X.115.2.336

Schmidt, M. (1996). Rey auditory verbal learning test: A handbook. Los Angeles: Western Psychological Services.

Shin, N.Y., Lee, T.Y., Kim, E., \& Kwon, J.S. (2014). Cognitive functioning in obsessive-compulsive disorder: A meta-analysis. Psychological Medicine, 44(6), 1121-1130. http://doi.org/ 10.1017/S0033291713001803

Skapinakis, P., Caldwell, D.M., Hollingworth, W., Bryden, P., Fineberg, N.A., Salkovskis, P., ... Lewis, G. (2016). Pharmacological and psychotherapeutic interventions for management of obsessive-compulsive disorder in adults: A systematic review and network meta-analysis. The Lancet Psychiatry, 3(8), 730-739. http://doi.org/10.1016/S2215-0366(16)30069-4

Snyder, H.R., Kaiser, R.H., Warren, S.L., \& Heller, W. (2015). Obsessive-compulsive disorder is associated with broad impairments in executive function: A meta-analysis. Clinical Psychological Science, 3(2), 301-330. http://doi.org/10.1177/ 2167702614534210

Spencer, S.J., Steele, C.M., \& Quinn, D.M. (1999). Stereotype threat and women's math performance. Journal of Experimental Social Psychology, 35(1), 4-28. http://doi.org/10.1006/jesp.1998.1373

Steele, C.M. (1997). A threat in the air. How stereotypes shape intellectual identity and performance. The American Psychologist, 52(6), 613-629.

Steele, C.M., \& Aronson, J. (1995). Stereotype threat and the intellectual test performance of African Americans. Journal of Personality and Social Psychology, 69(5), 797.

Stengler-Wenzke, K., Beck, M., Holzinger, A., \& Angermeyer, M.C. (2004). Stigmatisierungserfahrungen von Patienten mit Zwangserkrankungen [Stigma experiences of patients with obsessive compulsive disorders]. Fortschritte der Neurologie und Psychiatrie, 72(1), 7-13. http://doi.org/10.1055/s-2003-812450

Stip, E., Caron, J., Renaud, S., Pampoulova, T., \& Lecomte, Y. (2003). Exploring cognitive complaints in schizophrenia: The subjective scale to investigate cognition in schizophrenia. Comprehensive Psychiatry, 44(4), 331-340. http://doi.org/ 10.1016/S0010-440X(03)00086-5

Suhr, J.A., \& Gunstad, J. (2002). "Diagnosis threat": The effect of negative expectations on cognitive performance in head injury. Journal of Clinical and Experimental Neuropsychology, 24(4), 448-457. http://doi.org/10.1076/jcen.24.4.448.1039

Tallis, F. (1997). The neuropsychology of obsessive-compulsive disorder: A review and consideration of clinical implications. British Journal of Clinical Psychology, 36(1), 3-20. http://doi. org/http://dx.doi.org/10.1111/j.2044-8260.1997.tb01226.x

Tallis, F., Pratt, P., \& Jamani, N. (1999). Obsessive compulsive disorder, checking, and non-verbal memory: A neuropsychological investigation. Behaviour Research and Therapy, 37(2), 161-166. http://doi.org/10.1016/S0005-7967(98)00075-8

Van Ameringen, M., Simpson, W., Patterson, B., Dell'Osso, B., Fineberg, N., Hollander, E., ... Zohar, J. (2014). Pharmacological treatment strategies in obsessive compulsive disorder: A cross-sectional view in nine international OCD centers. Journal of Psychopharmacology, 28(6), 596-602. http://doi.org/10.1177/0269881113517955

Volz-Sidiropoulou, E., Poll, E., Forkmann, T., \& Gauggel, S. (2010). Erweiterte Altersnormen zum Verbalen Lern-und Merkfähigkeitstest (VLMT) [Extended age norms for the Verbal Learning and Memory Test (VLMT)]. Klinische Diagnostik und Evaluation, 3(3), 226-243.

Warman, D.M., Phalen, P.L., \& Martin, J.M. (2015). Impact of a brief education about mental illness on stigma of OCD and violent thoughts. Journal of Obsessive-Compulsive and Related Disorders, 5, 16-23. http://doi.org/10.1016/j.jocrd.2015.01.003

Weisbrod, M., Kiefer, M., Marzinzik, F., \& Spitzer, M. (2000). Executive control is disturbed in schizophrenia: Evidence from event-related potentials in a Go/NoGo task. Biological Psychiatry, 47(1), 51-60. http://doi.org/10.1016/S0006-3223(99)00218-8

Wiesjahn, M., Jung, E., Kremser, J.D., Rief, W., \& Lincoln, T.M. (2016). The potential of continuum versus biogenetic beliefs in reducing stigmatization against persons with schizophrenia: An experimental study. Journal of Behavior Therapy and Experimental Psychiatry, 50, 231-237. http://doi.org/10.1016/j.jbtep.2015.09.007 